\title{
A TECHNICAL AND ECONOMIC COMPARISON BETWEEN TRADITIONALLY EMPLOYED AND EMERGING FAULT LEVEL MANAGEMENT SOLUTIONS AT DISTRIBUTION VOLTAGES.
}

\author{
M.F. Khan*, A.L.L. Jarvis *, E.A. Young **, R.G. Stephen*** \\ * School of Electrical, Electronic and Computer Engineering, University of KwaZulu-Natal, Durban, \\ 4041,South Africa.E-mail: KhanMa@eskom.co.za and Jarvis@ukzn.ac.za \\ ** Institute of Cryogenics, Engineering Sciences, University of Southampton, United Kingdom. \\ E-mail:E.A.Young@soton.ac.uk \\ *** Technology, Eskom Holdings Pty Ltd.E-mail: StephRG@eskom.co.za
}

\begin{abstract}
Network fault levels are reported to be increasing and this is often attributed to an increase in network interconnectivity and localised generation. When the fault level at a substation increases beyond the rated value of the installed equipment, a power utility traditionally responded by either (i) replacing the equipment with higher rated equipment or, (ii) installing series reactors or, (iii) replacing the existing transformers with high impedance transformers. Using a South African case study, this paper compares both the effectiveness and financial viability of a superconducting fault current limiter (SFCL) against the traditional three options. When one also considers the operational or 'energy' cost associated with all these options it was found that a high capital cost was sometimes offset by lower energy costs over a 25 year service life. Regional prices of electricity and tariffs therefore have a significant impact on a utility's choice of fault management solutions.
\end{abstract}

Key words: fault level management, power system management, superconducting fault current limiters.

\section{INTRODUCTION}

A high fault level is not intrinsically undesirable as it is an indication of the strength and robustness of a power system, but it becomes so when it is larger than the rating of the installed equipment. It is often cited that bus-bar fault levels on power grids are continually increasing [1], [2]. This then requires an intervention to mitigate against the inherent operational and safety risks.

Fault levels are increasing, primarily due to network interconnectivity, in an effort to improve power delivery reliability, and an increase in generation to meet the demands of increasing growth [3]. Government and utility initiatives have also resulted in an increase in the number of independent power producers, co-generation schemes and micro-renewable projects and this is known to increase the local generating capacity of the network and thus the fault levels [4].

Current research towards the development of superconducting fault current limiters (SFCL) for large scale power grid applications has led to the establishment of long term pilot installations on existing power grids and test grids to prove operability and performance, for example, the recent installations at San Juan de Dios Substation in Mallorca (Spain) [5], and Icheon substation (Korea) [6]. These installations are testimony that SFCLs are now evolving to a position wherein it too may be considered as an effective means of fault level management. This is evident even in the developing world, for example, a recent study on the impact of SFCL inclusion to the Abu Dhabi $132 \mathrm{kV}$ network [7].

Eskom is one of the largest power utilities in the world and generates $95 \%$ of the electricity used in South Africa (nominal capacity of $41995 \mathrm{MW}$ ) [8]. It is also responsible for the South African national grid. The authors conducted a comparison between the current network fault levels and the installed switchgear at all of the substations on Eskom's distribution network and discovered that there were 82 substations wherein the busbar fault level exceeds the installed network circuit breaker ratings. Although this represents only a small component of Eskom's installed base (2.52\%), measures have already been put in place to manage this and the future risk associated with continually increasing busbar fault levels. SFCLs were not amongst the mitigation technologies considered as it was considered to be too expensive and complex an option.

South Africa also experienced a major energy crisis in 2008 when the ever increasing demand for electricity was unable to be met by the existing installed generation plants. They responded by launching a number of initiatives to promote large scale renewable energy development. The Renewable Energy Bids (REBID) process [9], wherein a ceiling tariff rate is set for each technology and interested parties bid for power purchase agreements, was the most successful of these initiatives.

The impact of localized renewable energy generation on distribution network fault levels has yet to be sufficiently researched owing largely to variations of their geographic 
location and size. The connection of generation sources in distribution networks, which were originally planned and designed to supply radial loads, would have a considerable impact on bus-bar fault levels [4].

This paper utilizes a network case study to investigate the impact of increased renewable generation on fault levels and by extension, its impact on installed circuit breaker ratings exceedance and any associated energy loss. The South African Distribution Network Code [10] states in Section 7.2.1(3) that when making an investment in the power network the following criteria must apply:

"...the need to invest must first be decided on technical grounds. All investments must be the least life-cycle cost technically acceptable solution...".

The contribution of this paper is to therefore confirm the technical suitability of the fault management options considered by power utilities today and to present a realistic life cycle financial comparison of SFCL's with existing solutions. This in turn, highlights the significance of the regional cost of electricity when determining which fault level management tool is most effective.

\section{FAULT CURRENT MITIGATION OPTIONS}

We focus on four fault current mitigation solutions. The option of network reconfiguration, for example, the action of operating with the MV bus-bar split was not considered. Although it is known that this would reduce the fault level and come at a zero cost, it would also result in a loss of network reliability and flexibility, which is an undesirable consequence for a power utility.

\subsection{Air core reactor}

The series connected air core reactor represents the traditional option for fault current management in a power network. It addresses the fault level problem by adding impedance to the network. It is a passive device that requires minimal maintenance, has a relatively small physical footprint and is available at a cost that is significantly lower than any of the other options considered. It is however continuously connected and therefore consumes a significant amount of electrical power. The associated volt drop is compensated for by on-load transformer tap changers that regulate the voltage on the MV busbar.

\subsection{High impedance transformer}

Standard power transformers on a conventional electrical grid are specified with a typical impedance of $8 \%$. High impedance transformers, with an impedance that ranges between $17 \%$ and $20 \%$, have been introduced by power utilities as a fault level management measure. This passive mitigation measure operates on the same electrical principle as an air core reactor and therefore shares many of its advantages and disadvantages. An advantage when compared to an air core reactor is that it requires no additional space in an electrical yard and is therefore an ideal option when a retrofit solution is required with limited additional space available.

When considered as a solution to lower the fault level due to the availability of localized generation on the MV busbar, the losses are not higher, as the energy loss is a function of the load current that passes through the transformer, and that load current is reduced when generation is introduced directly onto the MV bus-bar. High impedance transformers are understandably more costly but these are however available to Eskom via long term contracts at a small premium when compared to the price of a standard transformer for the various voltage options. It is therefore an ideal option for new installations where it is perceived that fault levels are, or will become, a concern. When utilizing this option however, a power utility must also consider the additional costs associated with increased strategic spares holding.

\subsection{Equipment "up-rating”/ upgrade}

As discussed above, high fault levels are not necessarily undesirable, so long as the fault level is below the design limits of the installed substation equipment. One of the options available to utilities is to therefore replace the installed equipment with equipment that has a higher short circuit withstand capacity. Of the equipment installed in a substation, the one that is typically found with the lowest short circuit withstand capacity is the installed switchgear.

The replacement of installed switchgear in a substation is a costly and time-consuming option. The existing equipment would need to be decommissioned and removed before the new equipment can be installed and commissioned and this requires an extended outage. This option is, however, ideally suited to identified substations where the installed equipment has passed or is nearing the end of its service life. The choice of merely replacing the equipment in a substation yard when it is identified that the fault level has increased beyond the equipment rating is also not always practical. For example, substation components like the substation earth-mat, would have been designed for a particular fault level, and would have to be strengthened to ensure compliance viz. touch and step potentials [11]. The significant advantages to the equipment uprating option are that there is no additional maintenance requirement or operation (energy loss) costs. 


\subsection{Superconducting fault current limiter}

Recent installations of resistive superconducting fault current limiters on power grids has propelled this technology from the laboratory into a potentially viable alternative for fault level management [5], [6]. The device operates by allowing load current to pass through superconductor tape/wire that have been cooled to below a critical temperature thereby presenting minimal additional resistance. When a fault is introduced, the current increases above a threshold value which causes the superconductor to change phase and introduce resistance into the system, within the first half cycle, thereby 'instantaneously' reducing the fault current.

The SFCL is either connected on the MV bus-bar as a replacement to the existing bus section circuit breaker or in series with the incoming feeder. When a SFCL replaces an existing bus-section circuit breaker, it results in reduced operational flexibility. To overcome this, it is recommended that instead of replacing a bus section circuit breaker, a SFCL should be installed in series with one.

It is often stated that a SFCL is a zero energy loss solution, but this is not an entirely accurate reflection. Although, the SFCL dissipates minimal energy during normal operation due to the inherent resistive characteristics of superconductors, there still remains an energy requirement for this option. This is primarily for the SFCL cooling requirements and this energy loss is therefore independent of load current.

Other considerations need to be accounted for before installing a SFCL onto a power grid as its impact is not only limited to fault level management. SFCLs can influence power system stability [12] and substation reliability [13].

\section{CASE STUdY}

A network case study was selected as a way to compare the effectiveness of the various fault level management options. The criteria used to select the substation for the case study were:

$>$ One wherein the existing fault level was between $90-100 \%$ of the installed equipment rating

$>$ That it be situated in an area with the potential for localized generation projects

$>$ Enough space installed or adjoining to it that could accommodate all fault management options considered, and

$>$ Located within reasonable proximity to allow site visits to confirm equipment ratings etc.
The '90\% - 100\%' fault level criterion was selected to verify the potential impact that localized generation could have at substations where the circuit breaker ratings have not been exceeded as yet. The effectiveness of the different fault level mitigation options in response to the renewable energy technologies identified could also be assessed. The justification for the criteria regarding the location of the substation, is that there is an increased probability of localized generation when there are no space restrictions as would typically be found in an urban environment. A substation that met all the listed criteria was identified and selected. Figure 1 below is the single line diagram for the selected substation.

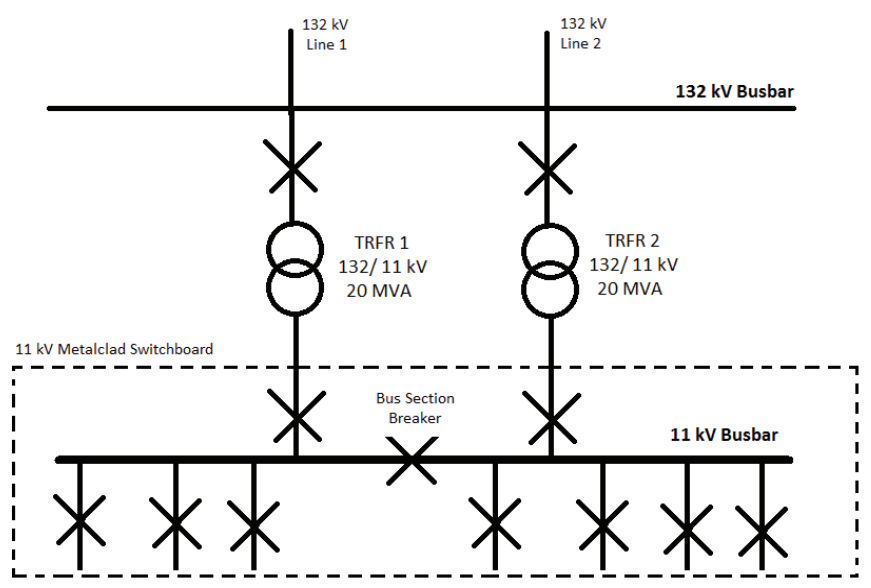

Figure 1: Operating diagram of the selected substation

\subsection{The impact of increased localized generation}

The network impact studies for the introduction of localized renewable energy generation was determined by considering projects where successful power purchase agreements have been concluded and is representative of installed capacity in megawatts (MW). This was considered to be a realistic means of determining the 'typical' sizes for the various types of renewable projects. An analysis of the REBID data from 2012 to 2014 is summarized in Table 1.

Table 1

Consolidated REBID Data (2012 -2014)

\begin{tabular}{|l|l|l|c|c|}
\hline & Wind & PV & $\begin{array}{l}\text { Small } \\
\text { projects }\end{array}$ & $\begin{array}{l}\text { Small } \\
\text { Hydro }\end{array}$ \\
\hline $\begin{array}{l}\text { Maximum } \\
\text { (MW) }\end{array}$ & 140.0 & 75.0 & 5.0 & 6.2 \\
\hline $\begin{array}{l}\text { Minimum } \\
\text { (MW) }\end{array}$ & 20.6 & 5.0 & 1.0 & 1.2 \\
\hline Average (MW) & 90.0 & 45.7 & 4.7 & 2.8 \\
\hline Median (MW) & 77.2 & 32.9 & 5.0 & 2.4 \\
\hline
\end{tabular}

The median for wind projects is $77.2 \mathrm{MW}$ and is therefore not considered for this study as a project of this magnitude would always be introduced on the HV busbar, and this study focuses on embedded generation projects on the MV busbar. There was only one 
hydroelectric and one biomass power purchase agreement for the period analysed. As both technologies would have utilized synchronous generation, only biomass, being the larger of the two with a capacity of $16 \mathrm{MW}$ was considered in the simulation below. The majority of projects in the 'small projects' category represented photovoltaic projects and were therefore modelled as such.

\subsection{Fault Level Simulations}

Simulation and analysis software, DIgSILENT PowerFactory ${ }^{\mathrm{TM}}$ was used to model the substation and the impact that various renewable energy projects could have on its existing busbar fault level rating. The median capacity for the various renewable technologies, as indicated in Table I, was simulated to observe the impact that a typical generation in-feed could potentially have on the existing fault level at the substation busbar. It was assumed for the purpose of these simulations that the system fault occurred at the substation MV bus-bar. The circuit breakers presently installed at the substation chosen for the case study has a fault level rating of 18.4 $\mathrm{kA}$.

The machine parameters (e.g. source impedance, sub transient reactance etc.) used for the different renewable generators simulated in this study were as obtained from the DIgSILENT ${ }^{\mathrm{TM}}$ library. All models contained within this library use parameters as obtained from manufacturers so that load flow studies that are conducted provide realistic results. Synchronous generators were modelled for hydroelectric schemes and the biomass scheme as they are traditionally favoured over asynchronous generators for large capacity machines. The invertor associated with photovoltaic power generation is modelled within the 'Photovoltaic Generator' element (Figure 2) and was modelled with a power factor of 0.95 .

No simulations are obviously required to confirm the effectiveness of 'up-rating' the installed switchgear. For this study an $11 \mathrm{kV}$ air core reactor with a rated inductance of $3.05 \mathrm{mH}$ per phase was selected as similarly specified units are currently utilized elsewhere on the network. Standardization was preferred to both reduce costs and minimize strategic spares holding. The high impedance transformer was simulated with an impedance of $20 \%$. The SFCL was not simulated as it has been shown to effectively limit the fault current of this magnitude and also has negligible system losses during normal operation [5], [6].

It was also noticed in the simulations that the utilization of the series air core reactor and the high impedance transformer had a negligible effect on the nominal tap position of the installed power transformers. Utilisation of these methods was therefore found to have a negligible effect on network voltage regulation.

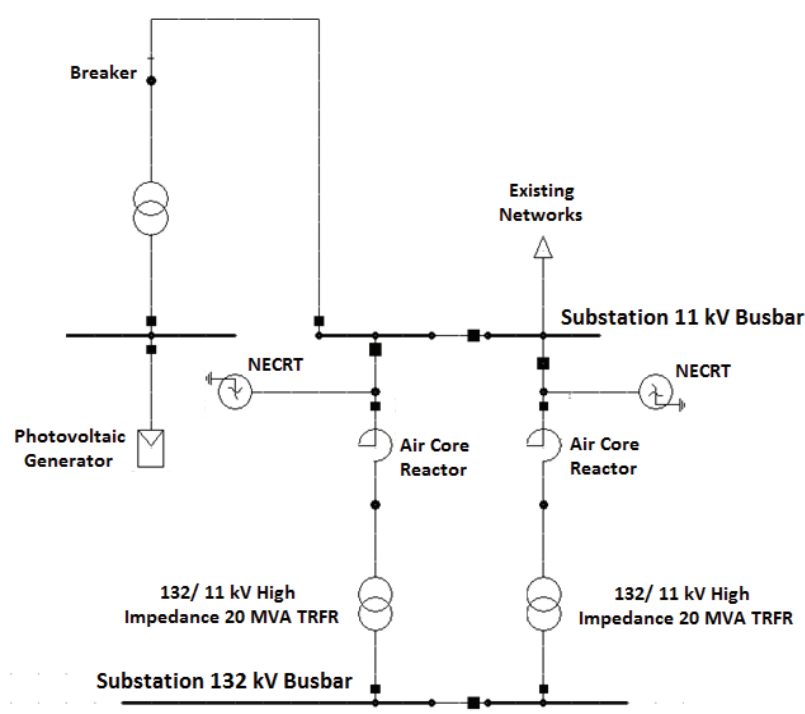

Figure 2: DIgSILENT ${ }^{\mathrm{TM}}$ models for a Photovoltaic Project with installed series air core reactors

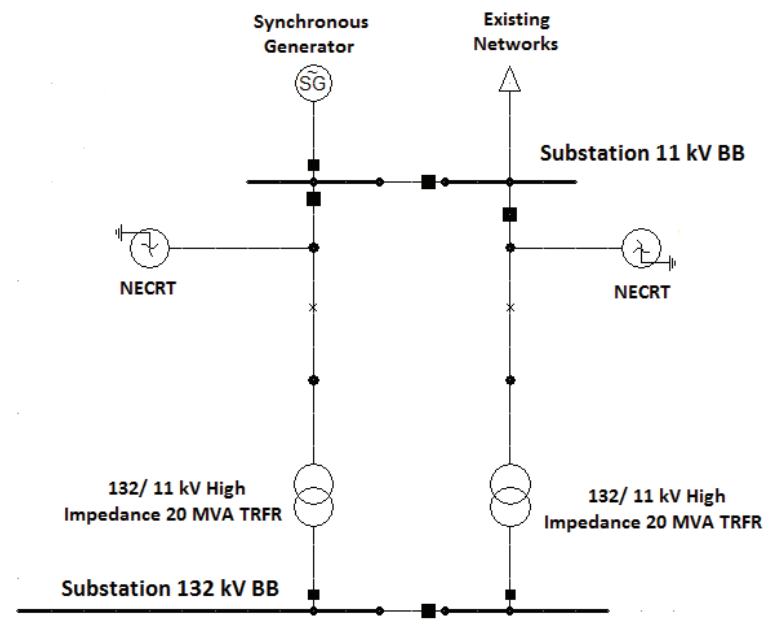

Figure 3: DIgSILENT ${ }^{\mathrm{TM}}$ models for a Synchronous generator utilizing a high impedance transformer

Table 2 summarises the impact on the simulated short circuit fault level when various renewable technologies are introduced to the local network. It also illustrates the effectiveness of the specified series reactor and the high impedance transformer as an effective fault level management device.

An analysis of Table 2 indicates that with the exception of the $5 \mathrm{MW}$ photovoltaic in-feed, all other simulations indicate that the circuit breaker rating would be exceeded for the various renewable technologies considered and an intervention would therefore be required to ensure operational safety. 
Table 2: Impact of renewable energy projects and mitigation options on busbar fault level

\begin{tabular}{|c|c|c|c|}
\hline & & $\begin{array}{c}3 \\
\text { phase } \\
\mathbf{I}_{\mathbf{S C}} \\
(\mathbf{k A})\end{array}$ & $\begin{array}{c}\text { ISC }_{\mathrm{SC}} \text { a } \\
\% \text { of } \\
\text { Circuit } \\
\text { breaker } \\
\text { Rating }\end{array}$ \\
\hline \multicolumn{2}{|l|}{ Existing Installation } & $\mathbf{1 7 . 8}$ & $96.97 \%$ \\
\hline \multirow{3}{*}{$\begin{array}{l}5 \text { MW Hydro } \\
\text { Generator } \\
\text { (Synchronous } \\
\text { Generator) }\end{array}$} & Impact on Fault level & 19.4 & $105.4 \%$ \\
\hline & Series Reactor & 9.4 & $51.1 \%$ \\
\hline & High Impedance Tx & 11.4 & $62.0 \%$ \\
\hline \multirow{3}{*}{$\begin{array}{l}16 \text { MW Biomass } \\
\text { Generator } \\
\text { (Synchronous } \\
\text { Generator) }\end{array}$} & Impact on Fault level & 24.1 & $131.0 \%$ \\
\hline & Series Reactor & 14 & $76.1 \%$ \\
\hline & High Impedance Tx & 16.1 & $87.5 \%$ \\
\hline \multirow{3}{*}{$\begin{array}{c}5 \text { MW Photo-voltaic } \\
\text { Plant } \\
\text { (Inverter) }\end{array}$} & Impact on Fault level & 18.1 & $98.4 \%$ \\
\hline & Series Reactor & 8.1 & $44.0 \%$ \\
\hline & High Impedance Tx & 10.1 & $54.9 \%$ \\
\hline \multirow{3}{*}{$\begin{array}{l}30 \text { MW Photo- } \\
\text { voltaic Plant } \\
\text { (Inverter) }\end{array}$} & Impact on Fault level & 19.6 & $106.5 \%$ \\
\hline & Series Reactor & 9.7 & $52.7 \%$ \\
\hline & High Impedance Tx & 11.8 & $64.1 \%$ \\
\hline
\end{tabular}

\subsection{Energy Loss Calculations}

The energy loss and cost associated with different fault current mitigation methods needs to be considered in order to determine the total life cycle cost.

The 'equipment upgrade' option would result in a zero energy loss and although a SFCL has negligible losses during normal operation, the energy required by the cryogenics require consideration. This was obtained by referencing the normal load current at the selected substation to the power loss associated with the design of an installed SFCL [5] i.e. the maximum cooling loss at room temperature was estimated to be $8500 \mathrm{~W}$ at typical network load current.

The energy loss associated with the use of a series core reactor and a high impedance transformer was simulated using DIgSILENT ${ }^{\mathrm{TM}}$. A typical daily load profile for this network (with morning and evening peaks) was modelled at the selected substation to determine the increase in energy loss when utilizing either an air core series reactor or a high impedance transformer for a day. This was then used to determine the annual operational (energy) cost. Table 3 shows the daily energy usage increase for the various fault management technologies identified over the installed installation.

Table 3: Daily energy requirements associated with the fault current mitigation methods identified

\begin{tabular}{|l|c|}
\hline & Energy increase (kWh) \\
\hline High Impedance Transformer & 633.7 \\
\hline Air core series reactor & 321.3 \\
\hline Equipment up-rate & 0 \\
\hline Superconducting fault current limiter & 204 \\
\hline
\end{tabular}

The energy cost associated with the total lifecycle was determined by using existing energy prices with an assumed annual inflation rate of $6 \%$ p.a to more accurately determine the lifecycle cost over 25 years. Table 4 summarises the total lifecycle costs for the options considered in this study.

\section{ANALYSIS OF FAULT LEVEL MANAGEMENT OPTIONS}

A power utility must consider two critical aspects before adopting a fault level mitigation solution, the technical and the financial. The case study above shows that all options considered will either lower the fault level to within specified limits or increase the existing fault level rating of the installed equipment. The financial impact for choosing a fault level mitigation solution therefore remains as the other critical aspect that requires consideration. In doing so, it is prudent to not merely consider the initial capital cost but to rather evaluate the total lifecycle cost, which includes the costs associated with purchase, operation and maintenance. At Eskom, primary plant equipment at substations are designed to have a service life of 25 years [14].

Capital costs were obtained from recent purchase invoices or contracted purchase agreements with Eskom and suppliers, with the exception of the SFCL, which was the reported acquisition price for an SFCL recently

Table 4: Lifecycle costs for fault level management technologies investigated ( Based on an exchange rate of R 14.21/ Euro and R 10.60/ \$ )

\begin{tabular}{|l|r|r|r|r|}
\hline & Series Reactor & Switchgear upgrade & High Impedance Tx & SFCL \\
\hline Capital Cost & $\$ 160,239$ & $\$ 650,822$ & $\$ 1,494,645$ & $\$ 1,742,736$ \\
\hline Energy Cost day & $\$ 15$ & $\$ 0$ & $\$ 10$ & $\$ 10,865$ \\
\hline Energy Cost (p.a) & $\$ 5,509$ & $\$ 0$ & & $\$ 3,498$ \\
\hline Energy Cost (25 years) & $\$ 302,238$ & $\$ 596,128$ & $\$ 191,907$ \\
\hline Total Lifecycle Cost & $\mathbf{4 6 2 , 4 7 7}$ & $\mathbf{\$ 6 5 0 , 8 2 2}$ & $\mathbf{\$ 2 , 0 9 0 , 7 7 3}$ & $\mathbf{\$ 1 , 9 3 4 , 6 4 3}$ \\
\hline
\end{tabular}


purchased by Western Power Distribution [15].

Maintenance costs were only a factor for an SFCL and it was assumed that maintenance would be undertaken on the cryo-cooler once a year. However, in the South African context this cost would be an assumption and it was therefore excluded from the case study with the understanding that the reader is aware that an additional undetermined maintenance cost is applicable to the SFCL whereas all other technologies evaluated would have a zero or negligible increase in maintenance costs.

Although the air core reactor has the lowest capital investment cost, it has a considerable energy cost with the high impedance transformer having the highest energy cost. Of all the options evaluated, the series reactor was found to be the most cost effective over a 25 year time period. The switchgear upgrade option was in this case study the next most cost effective option. As mentioned earlier, this study assumed that the earth-mat in the substation yard does not require uprating.

The installed circuit breakers at the selected substation were installed in 1978 and have therefore surpassed its service life of 25 years and are due for replacement. It therefore has a zero net asset value. Refurbishment of this substation would result in the circuit breakers being replaced, and the new circuit breakers on contract with Eskom are rated for a fault level of $25 \mathrm{kA}$ [14]. The maximum simulated fault current in Table II is $24.1 \mathrm{kA}$. Therefore, for this specific case study it appears that the solution to the problem of circuit breaker exceedance would be best addressed by "uprating" the circuit breakers even though it appears to not be the most cost effective from a life cycle costing perspective.

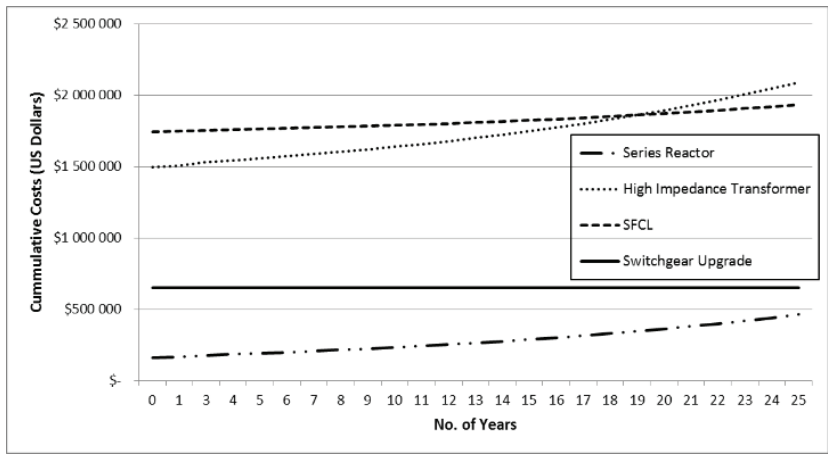

Figure 4: Accumulated cost of fault management options in South Africa. (Based on an exchange rate of R 14.21/ Euro and R 10.60/ \$)

The cost of utilizing a high impedance transformer was found to be the most energy intensive option. When considering the high capital cost of the high impedance transformer, one must bear in mind that this solution combines a fault level management tool with an essential item of plant in the substation and that the true financial cost of this fault level exceedance solution is therefore the total cost of the project less the remaining asset value of the existing transformers. As these transformers were purchased and installed in 1998, the true financial cost of this option considering depreciation, purely as a means to reduce the existing fault level, is therefore $\$ 1,310,434$ for the case study considered and is therefore financially not a viable solution in this instance. One should however also bear in mind that utilisisation of this option needs to be part of a much larger fault management philosophy as high impedance transformers would now be required to be purchased as part of the utility strategic spare fleet. Large-scale adoption of this philosophy could prove to be very expensive in the long term when factoring in the high energy cost of this option. It could however prove to be a viable option when building a new substation. The associated energy cost in this instance should be weighed against the increase in utilization of higher rated equipment.

Cooling costs for this study were determined using the calculated energy losses based on the 'Eccoflow' installation in Mallorca [5] which employs a closed cycle cooling system. Although an open cycle cooling system would utilize significantly less electrical energy, it would require increased specialized cryogenic maintenance and operation. The purchase price for a resistive SFCL was obtained from the recent procurement by Western Power Distribution (WPD) of two SFCLs to "future-proof" the Birmingham power distribution network [15]. This was the most recent cited example of a SFCL purchased to manage fault levels on a utility grid.

The very high initial capital investment cost for SFCLs remains the most significant factor in the high life-cycle cost determined for this option. It is understood that up to $3 \mathrm{~km}$ of high temperature superconductor (HTS) tape is utilized in the construction of a SFCL [5]. The cost of the HTS tape is known to be a significant factor in the overall capital cost of the SFCL. Tape prices are decreasing and will decrease even further with improved market penetration. The operating energy cost of the cryo-cooler was found to be comparable with that of the air core reactor however, it is clear to see that significant reductions in cryo-cooler efficiencies will still not affect the life cycle costs substantially.

For SFCLs to be viable for power utilities consideration in fault level management, extensive research and development on ways of reducing the initial capital cost are still required. Further analysis however, revealed that the financial viability of a solution is significantly dependent on the cost of energy. When one compares the life cycle costs of the various technologies considered in the South African context (Figure 4) to those costs if one assumed the energy cost to be five times more expensive (Figure 5), it is evident that the SFCL becomes much more viable option financially when the cost of energy is higher. It is generally accepted that the cost of energy in South Africa is significantly cheaper than that found in Europe, which could explain the justification for utilization of an SFCL in some European countries. 
Another contributing factor which would also favour the SFCL in some European countries is the lack of carbon reduction subsidies in South Africa. The earlier quoted purchase of two SFCLs for the Birmingham network [15] is financed significantly (EUR 20 Million) from the 'Low Carbon Networks Fund' which is an initiative for reducing carbon dioxide emissions.

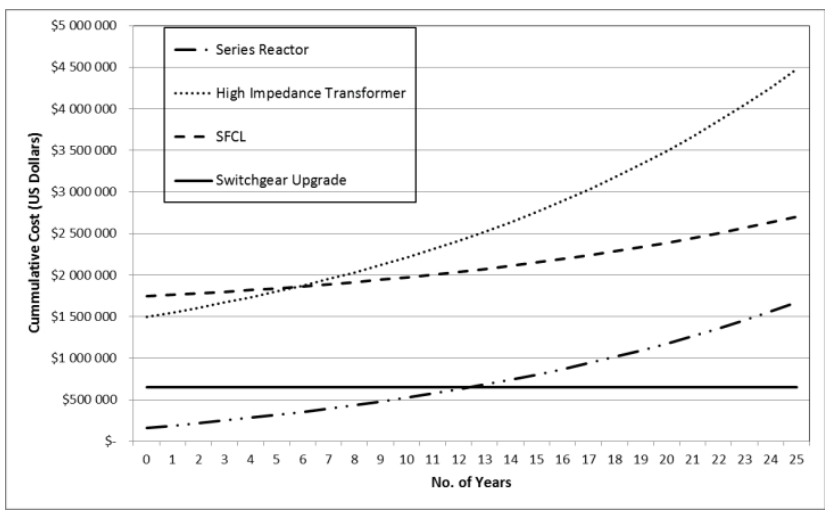

Figure 5: Accumulated cost of fault management options when assuming the cost of energy to be 5 times greater than the present South African case. (Based on an exchange rate of R 14.21/ Euro and R 10.60/ \$)

As Figure 5 illustrates, variation in the cost of energy has a significant impact on the lifecycle costs of the options considered. Intersection points clearly show after how many years options would a higher capital investment cost become more cost effective when compared to solutions that have a lower capital investment but higher energy requirement.

Figure 6 compares the lifecycle cost of a switchgear upgrade with a series reactor utilizing three different energy prices (the present, double and five times the South African energy price). It shows the circuit breaker replacement option becoming increasingly preferable as an option as the cost of energy increases.

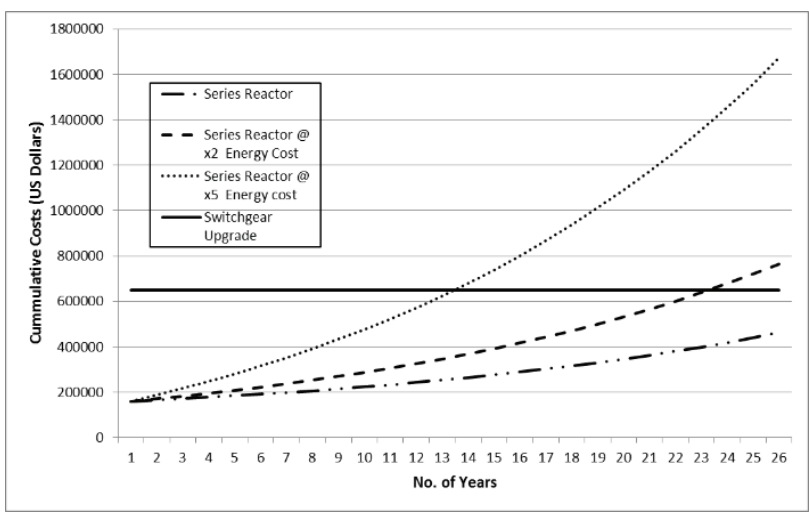

Figure 6: Accumulated cost of the switchgear upgrade option when compared to the accumulated cost of a series reactor at varying costs of energy. ( Based on an exchange rate of R 14.21/ Euro and R 10.60/ \$)

\section{CONCLUSION}

This paper shows that even small $(<5 \mathrm{MW})$ distributed generation projects have the potential to result in circuit breaker exceedance at a substation that would need to be addressed for operational and safety concerns. Of the fault level management technologies investigated for this case study, it was shown that the lowest 'energy cost' solution was not necessarily the most cost effective over a 25 year life cycle. There are many criteria to be considered when selecting an appropriate fault level management solution and these are, but are not limited to;

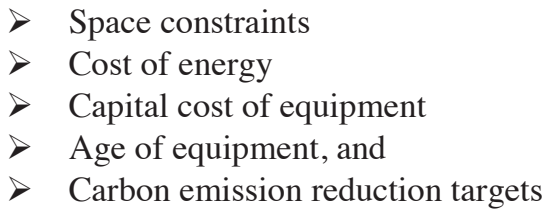

An important note to consider is that the SFCL is an emerging technology and therefore does not benefit as yet from the advantages of 'economies of scale'. The components of SFCLs are also continuously evolving at a rapid pace (eg. more efficient cryo-coolers, a reduction in the cost of HTS tape), which would result in a more competitive option in the future. Furthermore, utilization of a superconducting fault current limiter may address other power system related concerns e.g. the reduction of transformer inrush current [16] or a network voltage unbalance improvement [17]. However, technical challenges associated with emerging technologies need to also be taken into consideration e.g. specialized maintenance.

The cost of electricity used was found to have a significant impact on the life cycle costs for the various options considered. As the cost of electricity in South Africa is comparatively low when compared to other utilities around the world, SFCLs need to therefore significantly reduce their capital cost before it can become a viable fault level management option in South Africa. However continued electricity tariff hikes may significantly alter that variable, making it financially feasible to invest in devices that utilize less energy to undertake the same function.

It would not be feasible for a power utility to adopt a single strategy to address the challenges of increasing fault levels. One should rather evaluate the various options for individual substations on a case by case basis as there are factors other than just capital cost that one needs to consider before deciding on a solution. As an example, a substation that is space constrained may need to employ a high impedance transformer to lower fault levels even though research indicates that it is the most expensive option from a lifecycle cost. 


\section{REFERENCES}

[1] J. R. Prigmore, J.A. Mendoza, G.G. Karady, "Comparison of Four Different Types of Ferromagnetic Materials for Fault Current Limiter Applications," IEEE Trans.Power Delivery, Vol. 28 No. 3, July 2013, pp $1491-1498$.

[2] B. W. Lee, J. Sim, K. B. Park, and I. S. Oh, "Practical Application Issues of Superconducting Fault Current Limiters for Electric Power Systems," IEEE Trans. Appl. Supercond. , Vol. 18, No. 2, June 2008, pp $620-623$.

[3] C.J. Mozina, "Impact of Smart Grid and Green Power Generation on Distribution Systems", IEEE Trans Ind. Applicat., Vol 49, Issue 3, 2011, 06175625 .

[4] Y.M. Atwa et al., Optimal renewable resources mix for distribution system energy loss minimization", IEEE Trans.Power Syst., Vol 25, No. 1, Feb 2010, pp 360 - 370.

[5] M. Noe, A. Hobl, P Tixador, L Martini, and B Dutoit, "Conceptual Design of a $24 \mathrm{kV}, 1 \mathrm{kA}$ Resistive Superconducting Fault Current Limiter," IEEE Trans. Appl. Supercond. 235600304.

[6] M. J. Kim et al., "The application of fault current limiter at Icheon substation in Korea," $1^{\text {st }}$ International Conference on Electric Power Equipment - Switching Technology (ICEPE-ST), 2011, pp $362-365$.

[7] M.S. El Moursi, R Hegazy, "Novel technique for reducing the high fault currents and enhancing the security of ADWEA power system", IEEE Trans. Power Syst., Vol. 28, No. 1, Feb 2013, pp 140 148.

[8] http://integratedreport.eskom.co.za/pdf/fullintegrated.pdf (accessed on 02 July 2015)
[9] NERSA News, Official Newsletter of the National Energy Regulator of South Africa, Vol VI, Edition II, 2011.

[10]RSA Grid Code Secretariat (2014). Distribution Network Code Version 6.0, July 2014.

[11] M. Mitolo, P.E. Sutherland, R. Natarajan, "Effects of high fault currents on ground grid design", IEEE Trans Ind Appl., Vol. 46, Issue 3, 04025469.

[12] G. Didier, J. Leveque, A. Rezzoug, " A novel approach to determine the optimal location of SFCL in electric power grid to improve power system stability", IEEE Trans. on Power Syst., Vol. 28, No. 2, May 2013, pp 978 - 984.

[13] M. Fotuhi-Firuzabad, F. Aminifar, and I Rahmati, " Reliability study of HV substations equipped with the fault current limiter", IEEE Trans. Power Delivery, Vol. 27, No. 2, April 2012, pp 610 - 617.

[14]R. Kelly, "Specification for $11 \mathrm{kV}$ and $22 \mathrm{kV}$ withdrawable pattern air insulated Indoor primary switchgear, Eskom Doc No. 34-1157, 2012.

[15]A. Afanoukoe, 'Nexan's supplies two superconducting fault current limiters for permanent use on Birmingham's distribution network," Nexans Press Release, Paris, March 312014.

[16]H. Seo et al., "Superconducting Fault Current Limiter Application for Reduction of the Transformer Inrush Current: A Decision Scheme of the Optimal Insertion Resistance," IEEE Trans. Appl. Supercond. Vol. 20, No. 4, Aug 2010, pp $2255-2264$.

[17] J. Huh et al., "Study on Voltage Unbalance Improvement Using SFCL in Power Feed network with Electric Railway System," IEEE Trans. Appl. Supercond. Vol. 23, No. 3, Jun 2013, 3601004 